\title{
ASPECTS Regarding Option Trading AND THE Role of The Clearing House in This Process
}

\author{
VANCEA, S. \& HORJA, I.M.
}

Abstract: The present paper tries to bring into focus the major role of the Clearing House in the option trading process. The information that we used and reworked was collected from three important sources: literature review, official reports of Sibex (Sibiu Stock Exchange), official reports of Central Depository and Financial Supervisory Authority. The Option Clearing House runs a mathematic calculation and a risk evaluation for investors who have open option position. The paper explains the method of margin calculation for investors who write futures option.

Key words: option, option trading, derivative instruments, risk management
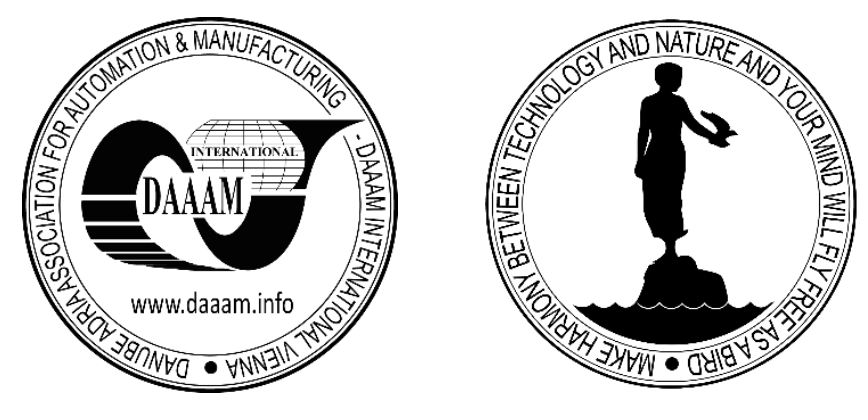

Authors' data: Univ. Dr. Lecture. Vancea, S[maranda]*;Associate Professor Dr. Horja, I[oana] M[onica]**, *University Dimitrie Cantemir, Bodoni Sandor 3-5, 540545, Targu Mures, Romania, ** University Dimitrie Cantemir, Bodoni Sandor 3-5, 540545, Targu Mures, Romania, smarandavancea@yahoo.com, moni_horja@yahoo.com

This Publication has to be referred as: Vancea, S[maranda] \& Horja, I[oana] M[onica] (2016). Aspects Regarding Option Trading and the Role of the Clearing House in This Process, Chapter 31 in DAAAM International Scientific Book 2016, pp.343-350, B. Katalinic (Ed.), Published by DAAAM International, ISBN 978-3902734-09-9, ISSN 1726-9687, Vienna, Austria

DOI: $10.2507 /$ daaam.scibook.2016.31 
Vancea, S. \& Horja, I. M.: Aspects Regarding Option Trading and the Role of the C...

\section{Introduction}

Defining options, as derivatives, is not a polemical issue in scientific literature. The definitions found in the literature converge to a common denominator, namely, coverage of the defining elements of the instrument. Which are these? Surely we will point out, as we highlight the most representative conceptual approach of this instrument. In a first conceptual note that options "are essentially standardized contracts that are part of financial derivative securities as well as futures contracts, that are instruments for negotiation" (Dragoescu, 2005). So the options are forward contracts, but with standardized clauses. In fact, from such a feature, some authors define very simple options: "option contracts are also called premium contracts"(Pop, 2009), highlighting in this way which gives the particularity of this derivative.

The presented definitions have already outlined some important options' milestones, such as: option is a contract, not only standardized, but also premium. But these definitions are brief and do not capture the essence of instrument which is why we also have other definitions that emphasize the relationship between contractual parties established after the first negotiation between partners. "Contract option is an agreement between two parties whereby one of them (the buyer) acquires from the other (the seller, the writer) by paying a premium (or premium), the right, but not the obligation to buy (call) or them sell (put) a specified quantity of a good at a specified price (the strike price) during a defined period. "(Dufloux, 2002)

\section{Previous studies regarding the risk assessment for futures option in Romania}

Risk assessment for options traded on capital markets is motivated by establishing fair margin (deposit guarantee) required by holding short positions within an options market. The process is running by a Clearing House. The risk assessment involves assessing the risk of the entire portfolio (Futures and Options), related to a type of derivative instrument and maturity, owned by a clearing member in the market because, in terms of the Clearing House, the clearing member account is unique, in it is recorded all transactions in options and futures contracts. The main request is to cover all open positions on both the futures and options.

Romanian Clearing House $(\mathrm{RCH})$ is responsible for the risk assessment of futures options contracts traded on Sibex (Sibiu Stock Exchange). Effective realization of the operation, as I explained, is based on two elements:

- Pyramidal system of accounts opened by RCH compensatory members

- Centralizing what the $\mathrm{RCH}$ calculations made in each account opened for clearing members.

The assessment is made on a range located around the current price quotation, and aims to determine the maximum loss that can be registered on this interval. 


\section{Some Basic Principles of Futures Option Risk Assessment in Sibex Market}

Option traded operational risk assessment is motivated by establishing fair margin (deposit guarantee) required by holding short positions within a market of options. This operation is made entirely by the Clearing House.

The risk assessment involves assessing the risk of the entire portfolio (Futures and Options), related to a type of derivative instrument and maturity, owned by a clearing member in the market because, in terms of the Clearing House account clearing member it is one in which is recorded boughs transactions in options and option trades on futures contracts. It is important that overall the account balance of open positions to cover the all the futures and options open position.

Romanian Clearing House (CRC) is responsible for the option risk assessment traded on the Futures Sibex Market.

The effectiveness realization of the operation is based on two elements:

- Pyramidal system of accounts opened by CRC compensatory members for them and their clients ;

- Centralizing the CRC calculations made in each account opened for clearing members.

The assessment is made on a range located around the current price quotation, and aims to determine the maximum loss that can be registered on this interval.

Following the approach practiced at $\mathrm{CRC}$ we found that:

- Risk assessment is done by listing open positions portfolio at strike prices in the range previously provided;

- Rated portfolio includes open futures and options positions that fall within the target range money, regardless of their exercise price;

- Maximum risk arises if a portfolio consisting solely of sales of options.

Within the established range, portfolio value is calculated cumulatively on Futures and Options for the same contract and maturity, the range ends and the exercise prices of the options. This calculation can reveal:

- The biggest negative value represents the portfolio risk;

- If the portfolio value is higher or equal to zero at all points of the interval, the risk is zero;

- If the portfolio has only positive values, the lowest value is the amount mentioned under "Options", and the risk is zero.

\section{The Method of Margin Calculation for Investors Who Write Options}

Margin determined by the Clearing House is based on the maximum loss (risk) that an option position may be suffered, in the range of the standard deviation. The calculation is performed by the Clearing House for "each derivative financial instrument and maturity, margins and results are added together, thereby achieving required margin for the full account of the clearing member." 
Vancea, S. \& Horja, I. M.: Aspects Regarding Option Trading and the Role of the C...

Based on these principles, based on the examples of risk calculation previously submitted and trading regulations applicable in Sibex (Sibiu Stock Exchange) market, we bring into focus the following rules for calculating the margin for (futures options writers):

\section{At the money futures option writing position, with no futures cover:}

Margin $=100 \%$ of the required margin on futures contracts (that are underlining in option) plus position margin

2. In the money futures option writing position (option strike < Futures quotation - in the case of CALL's; Option strike $>$ Futures quotation - in the case of PUT's)

- Margin $=100 \%$ of the required margin on futures contracts (that are underlining in option) plus position margin

- In this market situation, the option price required by the option writer cannot has a smaller value than the difference between quotation and strike (the options price cannot be smaller than the intrinsic value of the option)

3. Out the money futures option writing position (option strike $>$ Futures quotation - in the case of CALL's; Option strike < Futures quotation - in the case of PUT's)

- $\quad$ withheld margin gradually, as the Futures quotation approaches the strike price

Example: The Calculation of margin required for on CALL written, at a 40.000 strike price, futures contract underline with a futures margin of 5000 .

Margin shall be settled as following:

- Under a Futures quotation of 35 000: margin $=0$, because the option is out the money, there is no risk for the seller (writer) to be exercised

- As the Futures quotation approaching the option's strike, the margin will be deducted as following:

- Futures rating: $36000 \rightarrow$ margin $=1000 / 5000=$ option sold $($ margin Futures) - 4000 (quotation difference -strike price)

- Futures rating: $37000 \rightarrow$ margin $=2000 / 5000=$ option sold (margin Futures) - 3000 (quotation difference -strike price)

- Etc ... until:

oRating: $40000 \rightarrow$ when detained margin will be 5,000 / option $=$ Futures margin, because the money call option became margin required on the short call position is $100 \%$ of the margin that is underlying Futures contract

Once the option is in the money, the Futures quotation is above the exercise price, so it can be exercised by the purchaser. This involves additional risks for the seller. So, in order to hedge this supplementary risks, the options writer is required to put a margin on futures + maintenance margin, calculated by the Clearing House in a manner that is a compensation for daily Futures varying.

Such a mechanism to settle futures options margins practiced in the regulated market of derivatives in Sibiu, is an solid argument that futures options negotiations are actually all trades in the Futures markets. 


\section{Managing accounts for the Clearing Members}

In direct connection with the account management on clearing members, the Clearing House runs specific operations, starting in the moment of the in exchange floor transaction are settled. At that time, after checking that the initial margins for open short positions, and the availability of the prime for open long positions, The Clearing House starts to continuously monitoring of those accounts.

\section{What can determine such continues monitoring?}

The answer to such a question is related to the mechanism of running transactions with American-style options that can be exercised at any time during their life (regardless of the underlying asset). The decision to exercise the contract by investors with long position is based on achieving profits. So, when is profitable to exercise? When short investors are liable to be exercise, so must have sufficient resources to fulfil contract execution?

All answers are provided by the information in the bank account of each investor. But, as I said before, these accounts of the investors is actually part of the pyramidal system of accounts managed by the Clearing House.

Clearing House realize the risk tracking through a computerized system, for each type of contract, for each clearing member, using the principles presented in the preceding paragraphs. The results of that calculation are propagated through a backoffice soft to each clearing members accounts, and then, propagates results to SSIFs where every investor in the market has made the request for opening an account. In Romanian practice, to gain the role of a clearing member is conditioned by the quality of the investment firm (not vice versa), so, in most cases, circuit information in this pyramid is shortened because SSIF acquits in which the investor has the account is a clearing member.

In fact, this mechanism briefly described managed by the Clearing House has as a result of marking to market quotations accounts depending on the evolution of the underlying reference market. Marking to market generally has as a result the calculation of gain / loss position option for every investor, for each type of contract with the open position. The Romanian Clearing House Regulations stress that "the situation daily account clearing member has four components:

1. The amount in the account $=$ account turnover + profit $/$ loss + bonuses - fee;

2. Minimum gross profit options $=$ options deep in the money resulting from the calculation of portfolio value;

3. The risk margin required is the sum of all open positions;

4. Available amount / margin call

It appears that the amount available in the account is influenced by the marking to market of open positions, being an account surplus over the required margin for all open positions. The amount available in the account can be used to initiate new transactions or for withdrawn from account.

By marking to market, can achieve the margin call, where the amount available in the account is not sufficient to cover the required margin level daily. For a clearing member, calculation of the margin call is calculated per account, including "marking 
Vancea, S. \& Horja, I. M.: Aspects Regarding Option Trading and the Role of the C...

to market the results of the open of all contracts traded on that account", as the Romanian Clearing House Rules specific.

Recourse to the margin represents the amount to be deposited by the clearing member to complete the amount from your account until the margin calculated for those open positions. The margin call is sent explicitly by the clearing house in a daily report. The clearing member must conform to such notification "until 14 a.m. the next session trading through one of two variants of action or a combination of:

a. complete the amount in the account;

b. closure of a number of positions to ensure the cover margin decreased risk for open positions remaining

Marking to market a clearing member is performed both for the customer account (account aggregating results from customer accounts clearing member) and the house account. Regarding marking open customer accounts with the clearing member, this process is intended to provide information useful active participants in the market, as follows:

1. buyers choices is the ideal time to exercise American options traded (negative balance futility means of exercising the option);

2. sellers of options can know at all times what is available balance in the account;

3. a negative balance equivalent to a margin call to the vendor of choice;

4. for each active investor in the market transmit timely information resulting from marking to market as a trading statement;

5. importance of the awareness that the exercise of the option on futures contract open position in the futures market, which fall in the mark-to-market, which is why, when the account balance is positive (positive) can profit by accumulated only closing futures positions resulting from exercise.

In terms of margin calls related to customer account, the clearing member shall notify, through back-office software available, which customers must satisfy the margin call. If they do not respond, closing their corresponding positions will take place during the next exchange session, "when the first transaction of the clearing member will be to close out positions uncovered.'If the margin call is for the account of the clearing member house, the answer to this call must be made of the clearing member's own resources, in any form will not be used customer resources. Failure to observe the response to the margin call, the clearing member may entail the suspension of its situation in the clearing - settlement attended by signing the contract with the clearing house.

We find that managing client account opened by him through his broker to market clearing house, runs from the time of initiating the transaction. From this perspective we built according to its own vision, formed from the research issues in practice, a new building schematic summary that refers to the sequence of operations related to investor account management. Figure 1 outlines this approach us. Realization of Figure 1 focuses on information detailed in this chapter, in subchapter related steps art trades options, having as a goal so formalizing operations that succeed in managing client account and highlighting, in a simplified manner, part of the whole mechanism for the trading of options.

Figure 1 highlights the need for use within the complex process of managing a customer's account an impressive arsenal. 


\section{The sequence of operations related to options account management for customers}

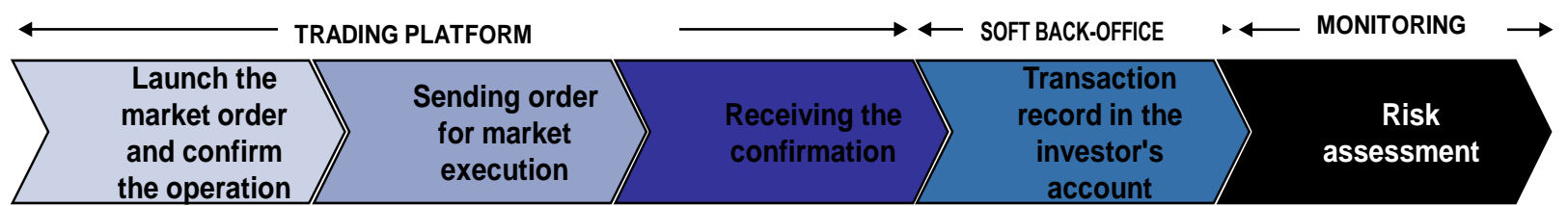

Concrete activities

\begin{tabular}{l}
\hline - Investor take the \\
initiative to carry out a \\
transaction \\
- Use some categories of \\
stock orders: stop or \\
limit \\
- Fill out the "order \\
exchange" conditions of \\
price, quantity, durability \\
require \\
- The broker confirms that \\
he understood the \\
conditions of the order \\
- Check for availability of \\
required margin launch \\
order
\end{tabular}
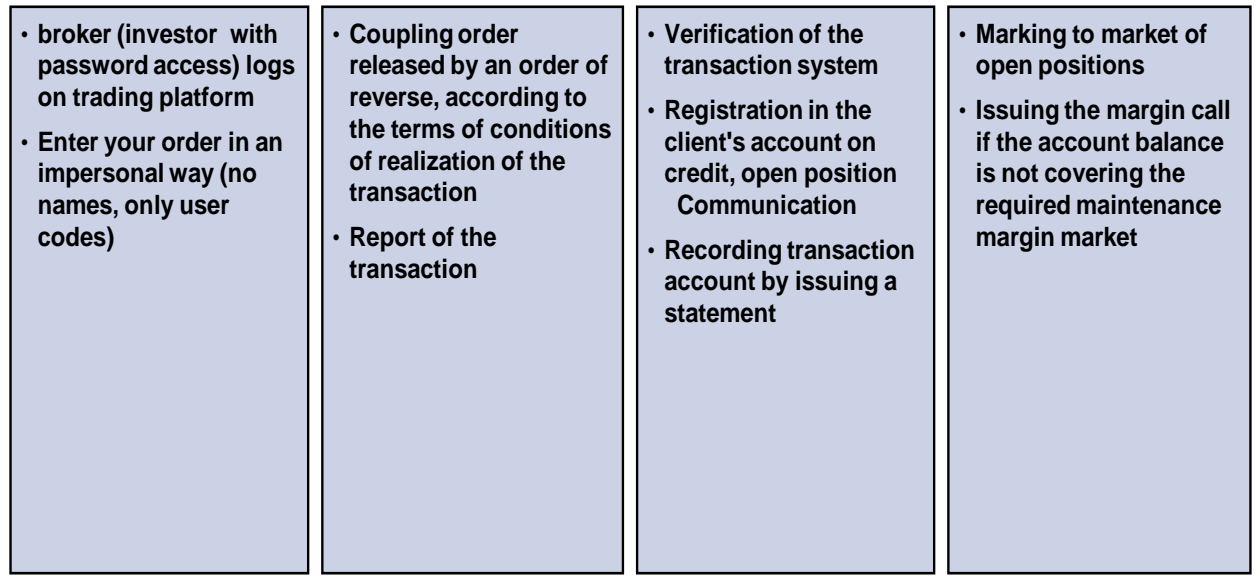

\section{Documents}

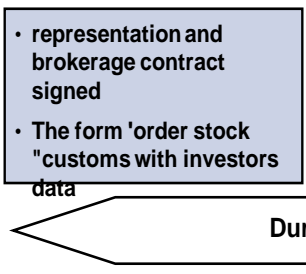

\section{"order stock" Form} accustomed and transmitted

Market Launched Orders Register

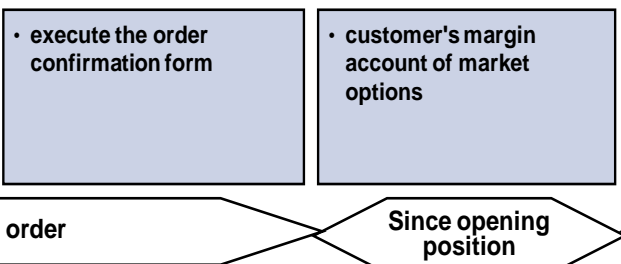

Fig. 1. Sequence operations of account management in options market

Later this information is taken into Clearing House software, which through the back - office software performed an interface standing between it, it's clearing members and investors from the opening position in the market and to its closure, as these contracts can run in contained in any time during his life. These issues will be discussed in detail below.

\section{Conclusion}

Trading options cannot be achieved without the contribution of Clearing House of options, performing specific operations (whose complexity and insufficient explanation in literature was a real occasion to highlight its contribution), such as records of transactions, evaluation the risk of open positions in the market, margin calculation for investors with sales position, updating accounts.

Options transactions evidence is simplified, being held by a pyramidal system of accounts managed by the Clearing House, for each clearing member. They shall keep a net positions record.

The risk assessment for futures options contracts is based on its assessment in the confidence interval set by the clearing house, around the futures price quotation, so determining the risk position option on a specific futures contract that the maximum 
Vancea, S. \& Horja, I. M.: Aspects Regarding Option Trading and the Role of the C...

loss calculated on the ends of this range reliable. The explanation of this mechanism is useful to highlight once again the interconnectedness between "market options" and "futures market".

Our proposal, in terms of expanding the range of options on other underlying assets, for example shares, relates to the implementation (by a process of consolidation of the market in Sibiu in a group of European exchange) a similar system for assessing dynamic risk for holdings of shares and it would be tantamount to holding a common platform (or a link) trading as stock options and actions that support those options are active.

On the basis of assessed risk level is determined the margin required for short options investors.

To prevent the insolvency of participants in transactions is necessary to implement such a system of risk assessment which guarantees the execution of contractual obligations, because in the market remain with open positions only investors who have coped with these risks.

\section{References}

Dragoescu, E. (2005), Inginerie financiară, Tg.Mureș: Dimitrie Cantemir Publisher Dufloux, C. (2002), Financial Markets (Translation), Bucharest:Economics Publisher Hull, J.C.(2014), Options, Futures, and Other Derivatives, Pearson Publisher, ISBN 13 978-0133456318

Hull, J.C. (2016), Fundamentals of Futures and Options Markets, Pearson Publisher, ISBN -13 978-0134083247

Pop, C. (2009), Pieţe financiare, Cluj-Napoca: Todesco Publisher

Vancea S., Horja, I. M. (2013), Aspects regarding the behavior of financial instruments investors in Romania, Academica Science Journal, Economica Series, No. 1 (2) - 2013, ISSN: $2285-8067$

Vancea S., (2009), The options utility in risk management in terms of global financial crisis, The 6th International Conference on Management of Technological Changes, 35 septembrie 2009, Alexandroupolis, Greece, ISBN (volII) 978-960-89832-8-1, p.629632

Vancea, S., (2009), Realisation and perspective on option trading in Romanian financial markets, Ph.D. Dissertation, Department Finance, Lucian Blaga University, City: Sibiu, Country: Romania

Vancea, S.; Horja,M.I; Avram, E.L.; Ignat, A.B.(2009). A Possible Trend of Option on Futures in Romanian Capital Market, In: Annals of DAAAM For 2009\&Proceedings of the 20th International DAAAM Symposium "Intelligent Manufacturing\&Automation: Focus on Theory, Practice and Education", Katalinic, B. (Ed.), pp. 14-17, 1615-1617, ISBN 978-3-901509-70-4,25-28 Nov 2009, Vienna, Austria 